\title{
Pestisit Uygulamaları İçin Optimize Edilmiş Koşullarda Sprey Karakteristiklerinin Belirlenmesi
}

\author{
Determination of Spray Characteristics in Optimized Conditions for Pesticide Applications
}

\author{
Altuğ KARABEY*1,a, Yunus ÖZKAN ${ }^{2, b}$, Bahadır SAYINCI $^{3, c}$, Faruk YEŞILDAL $^{4, d}$ \\ ${ }^{1}$ Van Yüzüncü Yıl Üniversitesi, Mühendislik Fakültesi, Makine Mühendisliği Bölümü, 65080, Van \\ ${ }^{2}$ Van Yüzüncü Yll Üniversitesi, Fen Bilimleri Enstitüsü, Makine Mühendisliği Bölümü, 65080, Van \\ ${ }^{3}$ Mersin Üniversitesi, Mühendislik Fakültesi, Makine Mühendisliği Bölümü, 33343, Mersin \\ ${ }^{4}$ Atatürk Üniversitesi, Mühendislik Fakültesi, Makine Mühendisliği Bölümü, 25240, Erzurum
}

• Geliş tarihi / Received: 23.03.2020 • Düzeltilerek geliş tarihi / Received in revised form: 04.05.2020 • Kabul tarihi / Accepted: 04.06.2020

$\ddot{O} \mathbf{z}$

Tarım küresel bazda gelişmekte olan büyük ve ciddi bir sektördür. Tarımda önemli bir araştırma konusu püskürtme yöntemiyle yapılan pestisit uygulamalarıdır. Sprey uygulama teknolojilerinin amaçlarından biri, bitkisel üretimde zararlı veya hastalık etmenlerinin seviyesini azaltmak için pestisitlerin doğru zamanda uygun tekniklerle önerilen dozda kullanılmasını sağlamaktır. Bu çalışmada, konvansiyonel pülverizatörlerde kullanılan ve tek noktadan atomizasyon sağlayan konik hüzmeli nozulun akış parametrelerinin damlacık çapı üzerindeki etkileri incelenmiştir. Bu amaç doğrultusunda, sabit ilaçlama hızı ve spreyleme açısı koşullarında üç farklı nozul-yüzey mesafesi $(70 \mathrm{~cm}, 85 \mathrm{~cm}, 100$ $\mathrm{cm}$ ), üç farklı işletme basıncı ( 6 bar, 8 bar, 10 bar) ve üç farklı nozul çapı akış parametreleri olarak belirlenmiştir. Deneyler farklı zamanlarda çift tekrarlı olarak yapılmıştır. Sprey uygulamalarından sonra suya duyarlı kağıtların yüzeyinden elde edilen damla lekesi görüntüleri işlenerek hacimsel çap ve damla homojenlik değerleri belirlenmiştir. Akış parametrelerinin damla çapına olan etkisini incelemek için grafikler çizilmiş ve değişimler yorumlanmıştır. Genel olarak, aynı nozul orifis çapı ve spreyleme mesafesinde; işletme basıncı artarken karakteristik damla çapları küçülmüş ve homojenlik katsayısı iyileşmiştir. Aynı işletme basıncı ve spreyleme mesafesi için nozul orifis çapları karşılaştırıldığında; orifis çapı arttıkça damlacık çapının arttığı ve homojenliğin azaldığı gözlemlenmiştir.

Anahtar kelimeler: Atomizasyon, Damlacık Çapı, Pestisit Uygulamaları, Sprey Karakteristikleri

\begin{abstract}
Agriculture is a large and serious sector developing on a global basis. An important research subject in agriculture is the pesticide applications performed by spraying method. One of the objectives of spray application technologies is to provide using at the recommended dosage of pesticides at the right time by using the appropriate application techniques in order to reduce the level of pest or disease factors at crop production. In this study, the effects of flow parameters on droplet diameter of single hollow-cone nozzle used on conventional sprayers were investigated. For this purpose, three different nozzle-surface distances $(70 \mathrm{~cm}, 85 \mathrm{~cm}, 100 \mathrm{~cm})$, three different operational pressure ( 6 bar, 8 bar, 10 bar) and three different nozzle orifice diameters were determined as flow parameters under conditions of constant speed and spray angle. The experiments were carried out in duplicate at different times. After spray application, the droplet spot images obtained from the water sensitive paper surfaces were processed and the volumetric diameter and homogeneity values were determined. In order to examine the effect of the flow parameters on droplet diameter, the charts were drawn and the variations were interpreted. In general, the characteristic droplet diameters were decreased and the homogeneity coefficient increased on the conditions of the same nozzle orifice diameter and spray distance as the operational pressure increased. Comparing nozzle orifice diameters for the same operational pressure and spraying distance, it was observed that the droplet diameter increased for the nozzles with large orifice diameter and the homogeneity value deteriorated.
\end{abstract}

Keywords: Atomization, Droplet Diameter, Pesticide Application, Spray Characteristics

\footnotetext{
*a Altuğ KARABEY; akarabey@yyu.edu.tr, Tel: (0533) 488 16 58, orcid.org/0000-0001-5799-4585

${ }^{b}$ orcid.org/0000-0002-7984-2635 $\quad{ }^{c}$ orcid.org/0000-0001-7148-0855 $\quad$ orcid.org/0000-0002-7307-3556
} 


\section{Giriş}

Ekonomik ve sosyal alanda meydana gelen gelişmeler göz önüne alındığında küresel bazda büyüyen ve gelişen en önemli sektörlerden biri tarımdır. Dünya-Gıda ve Tarım Örgütü kaynaklarına göre 2050 y1lına dek dünya nüfusunun dokuz milyara ulaşacağı ve buna paralel olarak dünya gıda ihtiyacının günümüzden daha fazla olacağ 1 tahmin edilmektedir. $\mathrm{Bu}$ kapsamda dünya gıda ihtiyacının gelecek dönemlerde de karşılanabilmesi için mevcut tarım alanlarının verimli bir şekilde kullanılması ve üretimde verim artışının sağlanması gerekmektedir. Tarımsal üretimde verim unsurlarını arttırmak için üretim girdilerinin kullanılması zorunludur. Bu kapsamda en önemli gider kalemini pestisit adı verilen tarım ilaçları oluşturmaktadır. Tarımsal üretimde kısa sürede etki gösterdiğinden yaygın bir mücadele yöntemi olarak kullanılan kimyasal yöntemde pestisitler s1v1 formda püskürtme yapılarak uygulanmakta ve bu amaçla pülverizatör adı verilen tarım teknolojilerinden faydalanılmaktadır (Günel vd., 2006; Sayınc1 vd., 2019).

Tarımsal üretimde zararlı, hastalık ve yabancı otlara karşı yapılan kimyasal mücadelenin etkili bir şekilde sürdürülememesi sonucunda yıllık ortalama \%30-40 civarında ürün kaybı oluşabilmektedir. Kimyasal yöntemlerin yerine biyolojik mücadele yöntemine başvurulsa da zararlı ve hastalıkların epidemi halinde yayılma riskinden dolayı pestisitlerin kullanımı çoğu durumda kaçınılmaz olmaktadır. Bilinçli ve zamanında yapılan bir kimyasal uygulama, zararlı popülasyonu etkili bir şekilde kontrol edebildiği gibi pestisit tüketiminin azalmasını ve böylece üretimde girdi masraflarının düşmesini sağlamaktadır (Dağ vd, 2000; Matthews, 2004; Tanış, 2019).

Birleşmiş Milletler Gıda ve Tarım Örgütü (FAO) kaynaklarına göre 2017 yılında dünyada 4.1 milyon ton pestisit tüketilmiş ve on yıl içinde tüketim yaklaşı1 \%9 oranında artmıştır (FAO, 2017). Pestisitlerin büyük bir çoğunluğu sıv1 formda püskürtme yapılarak uygulanmaktadır. Konvansiyonel yöntemlerde atomizasyon yoluyla üretilen damlacıkların bir kısmı sürüklenme nedeniyle hedef dışına taşınmaktadır. Pestisitlerin önerilen dozda hedefe ulaşmaması sonucunda yeterince biyolojik etkinlik sağlanamamakta ve uygulamaların tekrar edilerek pestisit tüketiminin artmasına ve hedef yüzeyde aşırı dozda birikime neden olabilmektedir. Böylece üretim maliyeti artmakta, bitkide fitotoksitite riski oluşmakta, çevre, toprak ve yeraltı su kaynakları kirlenmekte, zararlılarda direnç mekanizması gelişmekte, önemli olmayan bazı zararlılar ana zararlı konumuna geçmekte, yararlı faunanın öldürülmesiyle doğal denge bozulmakta, ürünlerde aşırı pestisit birikimine yol açmakta ve insan sağlığını tehdit etmektedir (Coates ve Palumbo, 1997; Yıldırım, 2000; Sidahmed vd., 2004).

Kültür bitkilerine zarar veren etmeni doğru teşhis etmek, ekonomik zarar eşiğine göre mücadelenin gerekliliğine karar vermek, mücadele yöntemini belirlemek ve kimyasal uygulamalarda doğru pestisiti kullanmak tarımsal mücadelenin başlıca gerekleri olarak kabul edilmektedir (Hassen vd., 2014). Ancak siv1 pestisit uygulamalarında nozul tipi ve işletme parametrelerinin uygun olmaması etkili maddenin yeterince taşınamamasına yol açmaktadır. $\mathrm{Bu}$ kapsamda atomizasyon uygulamalarında kullanılan pülverizatörlerde homojen yapıda damlacıkların üretilmesi, ilaçlı karışımın homojen bir şekilde hedefe taşınması, damlaların yüzeyi yeterince kaplaması ve uygulamalarda hedef dişı sürüklenmeyi minimize etmesi beklenmektedir (Ozkan vd.,1992). Bunun için pülverizatörlerde kullanılan nozulların atomizasyon karakteristiklerinin bilinmesi, bu karakteristiklere etkili faktörlerin ve aralarındaki interaksiyon etkilerinin belirgin şekilde ortaya konması gerekmektedir.

Pestisit uygulamalarında bitki ve iklim koşulları, uygulama hacmi, ilaçlama zamanı, atomizasyon yapısı, karışımın formülasyonu ve yüzey kaplama oranının mücadelenin başarısını etkileyen faktörler olarak belirtilmiştir (Çelen vd., 2007). Özellikle, bazı zararlı ve hastalık etmenleri ile mücadelede damlaların yaprak altına ulaşması gerekmektedir. Buna ek olarak, yaprak altına ulaşan damlaların, etki etmesi gereken yüzeyde koruyucu amaçlı kaplama sağlaması önem taşımaktadır (Sumner vd., 2000).

Atomizasyonda nozulların görevi aynı büyüklükte damlalar üretmek ve damlaların hedef yüzeyde homojen bir şekilde dağılmasını sağlamaktır. Sprey uygulamalarında yaygın olarak kullanılan nozul tiplerinden birisi konik hüzme deseninde püskürtme yapan nozullardır. Günümüzde hastalık, zararlı ve yabancı otlarla mücadelede elde edilen başarı, aynı zamanda yapılan ilaçlamanın ekonomik olup olmaması ile de yakından ilişkilidir. Kimyasal mücadelede kullanılan pestisitin ve su kaynaklarının kisitlı olduğu bölgelerde kullanılacak su miktarının azaltılabilmesi ilaçlamanın ekonomikliği açısından önem arz etmektedir. Sayınc1 ve Bastaban (2004), sera ortamında hiyar bitkisinde düşük hacimli biri hava akımlı iki farklı döner 
diskli el pülverizatörü ile sırt pülverizatörünü yaprak altında ilaç tutunması ve toprak yüzeyinde kalıntı miktarı açısından karşılaştırmışlardır. Araştırma sonucuna göre sirt pülverizatörüyle karşılaştırıldığında düşük hacimli el tipi döner diskli pülverizatörle yaprak altına ulaşan madde miktarı bitkinin üst, orta ve alt bölgelerinde sırasıyla $1.1,1.3$ ve 2.6 kat artmıştır. Hava akımlı döner diskli el pülverizatöründe ise madde miktarındaki artış sırasıyla $1.7,1.2$ ve 1.3 kat olarak belirlenmiştir. Toprak yüzeyindeki kalıntı miktarı sırt pülverizatörüyle yapılan uygulamaya göre yardımcı hava akımlı döner diskli pülverizatörle $\% 88$, düşük hacimli el tipi pülverizatörde ise $\% 69$ oranında azaldığ 1 belirlenmiştir.

Pestisit uygulamalarında kullanılan hidrolik memelerin pülverizasyon karakteristiği çoğunlukla ince, orta ve kaba yapılı kategoriye girmekte olup, damla spektrumu püskürtme basıncından önemli ölçüde etkilenmektedir (Sayınc1 vd., 2013). Hidrolik memelerde pülverizasyon karakteristiğinin farklı olması damlanın hedefe taşınma enerjisini, sürüklenme düzeyini ve terminal hızını etkileyerek damlaların hedefe taşınma potansiyelini ve penetrasyonunu etkileyebilmektedir (Sayınc1, 2016a; Sayınc1 vd., 2019). Zararlı etmenlerle mücadelenin etkin bir şekilde sürdürülebilmesi için pestisitlerin içerdiği etkili maddenin birim alana damlalar halinde belirli sayıda ulaşması gerekmektedir. $\mathrm{Bu}$ kapsamda damla yoğunluğu sistemik etkili pestisitler için minimum 20 adet $/ \mathrm{cm}^{2}$, kontak etkili olanlar için 50 adet $/ \mathrm{cm}^{2}$ olarak önerilmektedir (Çilingir ve Dursun, 2002). Uygulamada bu alt sınırlara ulaşmak için meme tipi değiş̧irilmekte ya da püskürtme basınc1 veya birim alana püskürtülen damla hacmi arttırılmaktadır.

$\mathrm{Bu}$ çalışmada atomizasyon uygulamaları için optimize edilmiş şartlarda (Tanış, 2019) konik hüzme deseninde püskürtme yapan nozullarla sabit spreyleme hızında uygulamalar yapılmış ve bazı akış parametrelerinin damlacık çap1 üzerindeki etkileri incelenmiştir. Bu sayede, bağbahçe ilaçlamasında uygun koşulları sağlayan veriler kullanılarak çevre korunmasına katk1 sağlanacağı ve etkin püskürtme uygulamaları ile ilaçlama verimi ve başarısının arttırılacağ öngörülmektedir.

\section{Materyal ve Yöntem}

\subsection{Materyal}

Deneysel çalışmalar, akış karakteristiklerini belirlemek amacıyla iki aşamada yürütülmüştür.
Uygulamalar Van Yüzüncü Yıl Üniversitesi Mühendislik Fakültesi Makine Mühendisliği Bölümü Akışkanlar Mekaniği Laboratuvarı'nda kontrollü şartlarda yürütülmüş ve hava koşullarının etkisi minimize edilmiştir. Sprey uygulamaları için özel olarak dizayn edilmiş bir deney düzeneği kullanılmıştır. Deneysel çalışmaların ilk aşamasında deney elemanları düzeneğe yerleştirilmiş, hızölçer ile hızlar tespit edilmiş ve akışkan basıncı manometre ile kontrol edilerek atomizasyon gerçekleştirilmiştir. Sprey uygulamalarında örnekleme yüzeyi olarak suya duyarlı kağıt (WSP, $28 \times 38 \mathrm{~mm}$ ) kullanılmıştır. İkinci aşamada WSP örnekleri taranmış ve görüntü işleme yöntemiyle damlacık çapı ve homojenlik değerleri belirlenmiştir.

Hareketli bir mekanizmanın kullanıldığı deney düzeneğinde zemin, $2 \mathrm{~mm}$ paslanmaz sac levhadan yapılmıştır, Mekanizmanın ana çatısı 30 $\times 30 \mathrm{~mm}$ metal profilden imal edilmiştir. Deney düzeneğinin ölçüleri $0.5 \times 5 \mathrm{~m}$ olup yüksekliği 2 $\mathrm{m}$ olacak şekilde imal edilmiştir (Şekil 1). Sistemde akışkan olarak hava ve su kullanılmıştır. Akışkanın basıncı pompa çıkışında bulunan bir regülatörle kontrol edilmiştir. Sistemde maksimum 10 bar basınç ile çalışılmıştır. Spreyleme hizl ise hiz kontrol ünitesiyle ayarlanmıştır. Deneyler sabit $1.2 \mathrm{~m} / \mathrm{s}^{\prime}$ lik spreyleme hızında gerçekleştirilmiştir. Deneylerde akışkanı taşıyan boruların zarar görmemesi için koruyucu esnek kılıflar kullanılmıştır.

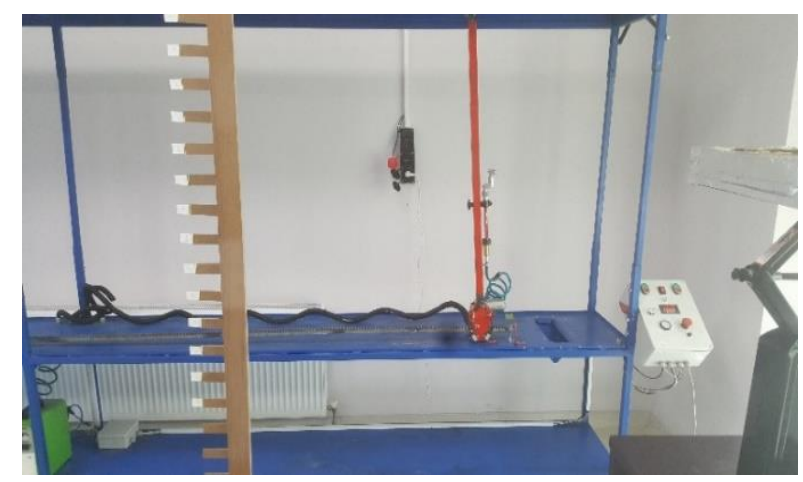

Şekil 1. Deney düzeneğinin görünüşü

Akışkanı depolamak için dikdörtgen prizma görünümünde 70 litre kapasiteli bir depo imal edilmiştir. İki katlı taşıyıcı sistemin birinci katında akışkan tankı, karıştırıcı motor, akışkanın debisini ölçmek için debi ölçer ve hidrolik pompa yer almaktadır. İkinci katta ise redüktörlü elektrik motoruyla tahrik edilen doğrusal hareketli mekanizma bulunmaktadır. Doğrusal hareket için 4 metre uzunluğunda kremayer dişli takımı kullanılmıştır. Mekanizmanın hareket hızı tahrik dişlisinin devri kontrol edilerek ayarlanmıştır. 
Devir kontrolü hiz kontrol panelinden ayarlanmıştır. Ayrıca nozul konum açısını ayarlamak için hareketli mekanizmaya mekanik bir sabitleme düzeni yerleştirilmiştir.

Doğrusal hareketli mekanizmanın otomasyonu için otomatik kontrol panosu kullanılmıştır. Kontrol panosu, deney sistemine ait komutların yorumlanmasını ve uygun kodlar ile eşleştirerek deney sisteminin mekanik hareketini, akışkanın spreyleme aşamasındaki basıncın ayarlanmasını ve deney sistemindeki hareket hızının otomatik olarak denetlenmesini sağlamaktadır. Deney sisteminde spreylemenin en önemli kısmı olan nozulun doğrusal hareketlerini otomatik olarak sağlayan elemandır (Şekil 2).

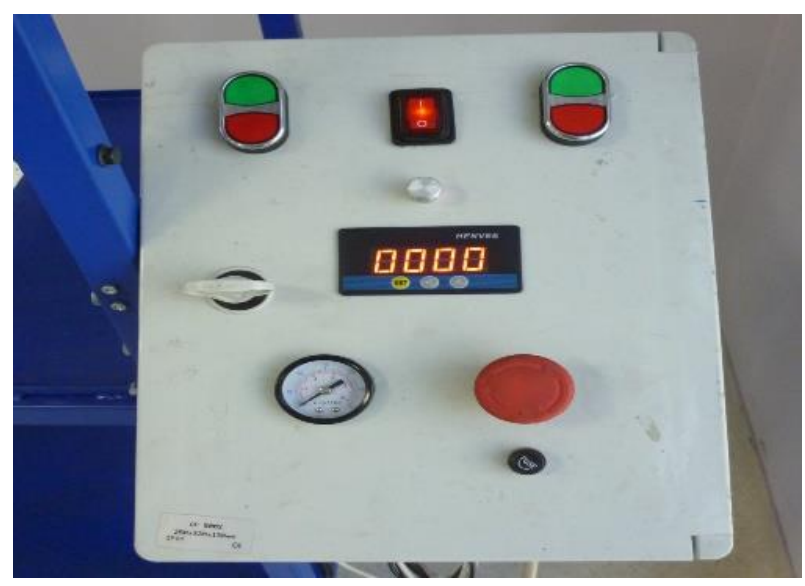

Şekil 2. Otomatik kontrol panosu.

Sprey uygulamalarında bahçe pülverizatörlerinde yaygin olarak tercih edilen paslanmaz çelikten üretilmiş içi dolu konik hüzmeli nozullar kullanılmıştır. Denemelerde $0.8 \mathrm{~mm}, 1.0 \mathrm{~mm}$ ve $1.5 \mathrm{~mm}$ orifis çaplı nozullar tercih edilmiştir (Şekil 3).

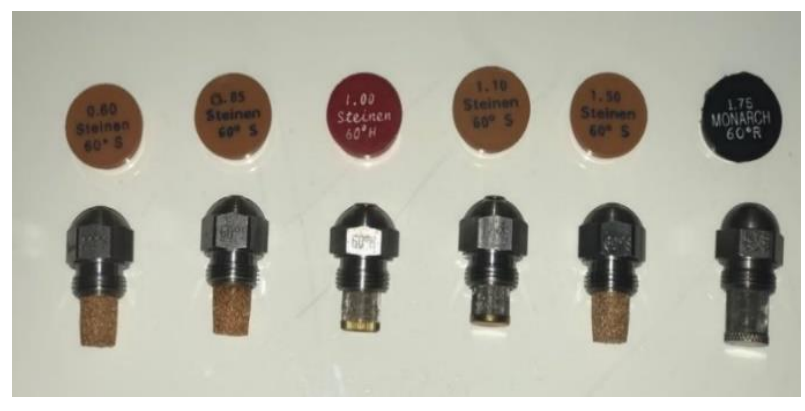

Şekil 3. Çalışmada kullanılan nozullar.

Suya duyarlı kağıtlar 2 metre yüksekliğinde kare profilden imal edilen bir direğe klipslerle sabitlenmiştir. Örnekler düşey düzlemde tek sıralı olarak $5 \mathrm{~cm}$ aralıklarla yerleştirilmiştir. Her uygulamada 13 adet WSP kullanılmıştır.

\subsection{Yöntem}

Sprey uygulamasindan sonra toplanan WSP örneklerinin her biri 600 dpi çözünürlükte (Marçal ve Cunha 2008), *.jpg uzant1lı resim dosyas1 olarak taranmış ve bilgisayar ortamına aktarılmıştır. Kart yüzeylerindeki lekelerin alanına bağlı olarak karakteristik damla çapları görüntü işleme yöntemiyle belirlenmiş ve analizlerde ImageJ (version 1.38x, Wayne Rasband, National Institutes of Health, US) yazılımı kullanılmıştır. Her bir WSP görüntüsünün ortalama grilik seviyesi $(g)$ belirlenmiş ve $t=0.38 g+78.75$ eşitliği kullanılarak eşikleme yapılmışıır (Sanches-Hermosilla ve Medina, 2004). Kart yüzeyindeki leke görüntüleri şekil analizine tabi tutulmuş ve Sæbø ve Wighus (2015) tarafindan bildirilen yönteme göre leke eliminasyonu yapılmıştır. Analiz sonucunda leke alanlarına bağlı olarak belirlenen eşdeğer çap değerleri 42.3 $[(25.4 / 600) \times 1000]$ ile çarpilarak (Uremis vd., 2004) leke çapı $\left(D_{s}, \mu \mathrm{m}\right)$ hesaplanmıştır. Sonuçlar $D_{g}=1.033 \cdot D_{s}^{0.879}$ eşitliğinde yerine yazılarak küresel damlaların çapı $\left(D_{g}, \mu \mathrm{m}\right)$ tahminlenmiştir (Franz, 1993). Damla örneklemesi için WSP yüzeyinden alınan görüntü dosyası Şekil 4'te gösterilmiştir.

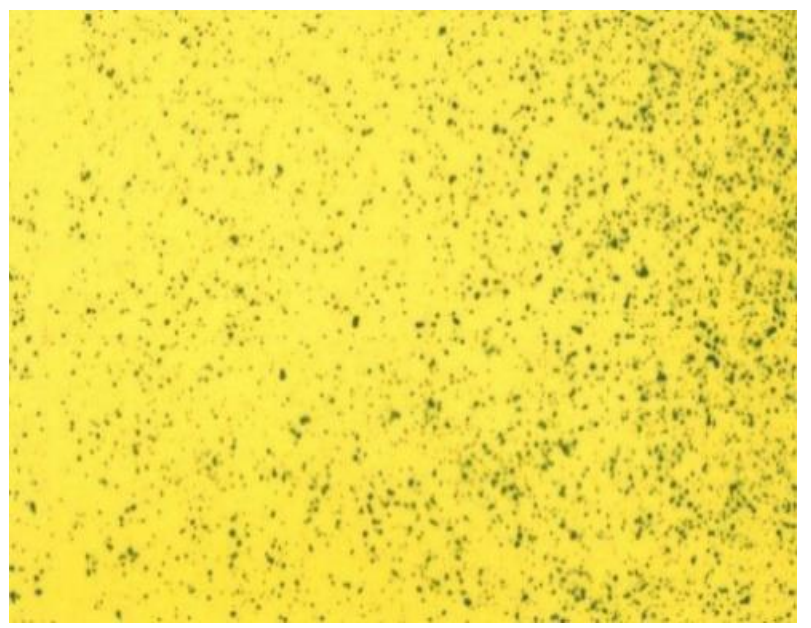

Şekil 4. Sprey uygulamasına ait WSP görüntüsü

Karakteristik damla çaplarını belirlemek için MS Excel'de makro program yazılmış ve 20 adet çap sınıfı aralığında analiz yapılmıştır (Srivastava vd., 1993). Karakteristik damla çaplarını ifade eden tanımlar ve kullanılan formüller (Nuyttens vd., 2007) Tablo 1'de belirtilmiştir. 
Tablo 1. Karakteristik damla çaplarına ait eşitlikler.

\begin{tabular}{ccccc}
\hline Aritmetik ort. çap & Yüzeysel ort. çap & Hacimsel ort. çap & Sauter çap1 & Homojenlik \\
\hline $\mathrm{D}_{10}=\sum_{\mathrm{i}=0}^{\mathrm{n}} \mathrm{d}_{\mathrm{i}} / \mathrm{n}$ & $\mathrm{D}_{20}=\left(\sum_{\mathrm{i}=0}^{\mathrm{n}} \mathrm{d}_{\mathrm{i}}^{2} / \mathrm{n}\right)^{1 / 2}$ & $\mathrm{D}_{30}=\left(\sum_{\mathrm{i}=0}^{\mathrm{n}} \mathrm{d}_{\mathrm{i}}^{3} / \mathrm{n}\right)^{1 / 3}$ & $\mathrm{D}_{32}=\sum_{\mathrm{i}=0}^{\mathrm{n}} \mathrm{d}_{\mathrm{i}}^{3} / \sum_{\mathrm{i}=0}^{\mathrm{n}} \mathrm{d}_{\mathrm{i}}^{2}$ & $\begin{array}{l}\mathrm{r}_{1}=\left(\mathrm{D}_{\mathrm{V} 0.9}-\mathrm{D}_{\mathrm{V} 0.1}\right) / \mathrm{D}_{\mathrm{V} 0.5} \\
\mathrm{r}_{2}=\mathrm{D}_{\mathrm{V} 0.5} / \mathrm{D}_{\mathrm{N} 0.5}\end{array}$ \\
\hline
\end{tabular}

Eşitliklerde kullanılan terimlere ait tanımlar aşağıda sunulmuştur.

$\mathrm{D}_{10}, \mathrm{D}_{20}, \mathrm{D}_{30}$ - aritmetik, yüzeysel ve hacimsel ortalama çaplar, $\mu \mathrm{m}$ (i: sinıf numarası, $\mathrm{d}_{\mathrm{i}}$ : $\mathrm{i}$. sınıftaki ortalama damla çapı, n: toplam damla sayıs1)

$\mathrm{D}_{32}$ - tüm damlaların toplam hacminin, toplam yüzey alanına oranı olarak aynı hacim/yüzey alanına sahip çap değeri (sauter ortalama çap, $\mu \mathrm{m}$ )

$\mathrm{D}_{\mathrm{N} 0.5}$ - toplamdaki damla sayısını iki eşit parçaya bölen çap değeri, (sayısal medyan çap, $\mu \mathrm{m}$ )

$\mathrm{D}_{\mathrm{V} 0.5}$ - hacimsel dağılımda toplam damla hacmini iki eşit parçaya bölen çap değeri (hacimsel medyan çap, $\mu \mathrm{m}$ )

$\mathrm{D}_{\mathrm{v} 0.1}, \mathrm{D}_{\mathrm{V} 0.9}$ - hacimsel dağılımda toplam damla hacminin sirasiyla \%10 ve \%90'l1k kısmına karşı1lık gelen çap değerleri, $\mu \mathrm{m}$

$\mathrm{V}_{100}, \mathrm{~V}_{200}$ - hacimsel dağılımda sirasılyla 100 ve $200 \mu \mathrm{m}$ 'den küçük çaplı damlaların yüzde oranı, $\%$

$\mathrm{r}_{1}-$ damla homojenliği, boyutsuz

$\mathrm{r}_{2}$ - damla homojenlik katsayıs1, boyutsuz

$\mathrm{D}_{\text {min }}$ - ölçülen en küçük çap değeri, $\mu \mathrm{m}$

$\mathrm{D}_{\text {mak }}$ - ölçülen en büyük çap değeri, $\mu \mathrm{m}$

Çalışmada sprey mesafesi, nozul orifis çapı ve işletme basıncı parametrelerinin damlacık çapına olan etkileri incelenmiş ve işletme koşulları Tablo 2 'de verilmiştir.

Tablo 2. Çalışmada incelenen parametreler ve değerleri.

\begin{tabular}{lccc}
\hline Parametreler & \multicolumn{3}{c}{ Seviyeler } \\
\cline { 2 - 4 } & 1 & 2 & 3 \\
\hline Sprey mesafesi (cm) & 70 & 85 & 100 \\
Nozul orifis çapı (mm) & 0.85 & 1.10 & 1.50 \\
İşletme basıncı (bar) & 6 & 8 & 10 \\
$\begin{array}{l}\text { Spreyleme hızı (m/s) } \\
\text { Sprey konum aç1s1 } \\
\text { (derece) }\end{array}$ & 1.2 & 1.2 & 1.2 \\
& $30^{\circ}$ & $30^{\circ}$ & $30^{\circ}$ \\
\hline
\end{tabular}

Bu çalışmada, pestisit uygulamaları için optimum sprey karakteristiklerinin belirlenmesinde, damlacık çapının performans karakteristiği olarak dikkate alındığı ve belirlenen dört parametre için Taguchi $\mathrm{L}_{9}\left(3^{4}\right)$ ortogonal dizisinin deney planı olarak seçilip optimum şartların belirlendiği çalışmaya ait sonuçlar kullanılmıştır (Tanış, 2019). Bu durum göz önüne alınarak yapılan bu çalışmada, Tablo 2' de görüleceği gibi nozulhedef yüzey mesafesi, nozul çap1 ve işletme basıncı üç seviyeli, diğer parametreler ise bir seviyeli seçilerek tek değişkenli deneysel analiz yapilmıştır. Bu modelde, optimum şartlara ait en etkili üç parametrenin farklı seviyelerdeki akış karakteristikleri ve atomizasyon sonucu oluşan damlacık çapına etkileri incelenmiştir. Çalışmada, pestisit uygulamalarında akış karakteristiklerini ve damlacık çapını etkileyebileceği ön görülen 27 adet deney şartına ait 54 adet deney yapılmıştır. Deneylerde bozucu ve tesadüfi faktörlerin etkisini gözlemleyebilmek için her deney farklı zamanlarda iki kez tekrarlanmıştır.

\section{Bulgular ve Tartışma}

Sprey uygulamalarına ait damla çapı ortalamaları ve diğer istatistikler Tablo 3'de sunulmuştur. Hacimsel medyan çapı $\left(\mathrm{D}_{\mathrm{v} 0.5}\right)$ değişim aralığına göre sprey uygulamalarında çok ince (VF), ince (F) ve orta (M) yapılı damlalar üretilmiştir (Hipkins ve Grisso, 2014; Albuz $^{\circledR}, 2016$; Hypro ${ }^{\circledR}$, 2018; Lechler $^{\circledR}$, 2018). Ortalama çap istatistiklerine göre damla dağılım spektrumunun geniş olduğu görülmektedir.

Tablo 4'de verilen hacimsel dağılımlara göre 100 $\mu$ m'den küçük çaplı damlaların oranı toplam hacmin neredeyse yarısını oluşturmaktadır. Üretilen toplam damla hacminin büyük bir kısmını ise $200 \mu$ m'den küçük çaplı damlaların oluşturduğu gözlenmiştir.

Damla spektrumunun tekdüzeliğini gösteren $r_{1}$ faktörünün değişim aralığı oldukça geniş olup, 1 değerinin altındaki değerlerde damla büyüklüğüne ait spektrumunun dar sınırlarda değiştiği, buna karşın 1 değerinin üzerinde olan dağılımda damla büyüklüğünün daha geniş bir aralıkta yayıldığı anlaşılmıştır. Damla homojenlik katsayısı $r_{1}$ 
açısından değerlendirildiğinde 1'e yakın değerler homojen yapıdaki damlacıkların oluştuğunu göstermektedir. $\mathrm{Bu}$ çalışmadaki $\mathrm{r}_{1}$ değerlerine göre sprey uygulamalar homojenliğinin oldukça anlaşılmaktadır. arasındaki damla farklı olduğu

Tablo 3. Damlaların sayısal, ortalama, medyan ve hacimsel çap değerleri.

\begin{tabular}{lcccccccc}
\hline İstatistikler & $\mathrm{D}_{10}$ & $\mathrm{D}_{20}$ & $\mathrm{D}_{30}$ & $\mathrm{D}_{32}$ & $\mathrm{D}_{\mathrm{N} 0.5}$ & $\mathrm{D}_{\mathrm{v} 0.1}$ & $\mathrm{D}_{\mathrm{v} 0.5}$ & $\mathrm{D}_{\mathrm{v} 0.9}$ \\
\hline Ortalama & 88 & 95 & 102 & 117 & 80 & 76 & 122 & 182 \\
Standart sapma & 30 & 34 & 36 & 43 & 36 & 34 & 46 & 69 \\
Min-mak & $60-226$ & $63-249$ & $65-264$ & $69-296$ & $54-240$ & $52-221$ & $69-300$ & $86-448$ \\
\hline
\end{tabular}

Tablo 4. Damla dağılımı ve homojenliği.

\begin{tabular}{lcccccc}
\hline İstatistikler & $\mathrm{V}_{100} \%$ & $\mathrm{~V}_{200} \%$ & $\mathrm{r}_{1}$ & $\mathrm{r}_{2}$ & $\mathrm{D}_{\min }$ & $\mathrm{D}_{\text {mak }}$ \\
\hline Ortalama & 44.9 & 86.3 & 0.90 & 1.60 & 38 & 465 \\
Standart sapma & 21.3 & 24.6 & 0.22 & 0.45 & & \\
Min-mak & $13-96$ & $3.4-100$ & $0.50-1.60$ & $1.22-3.44$ & & \\
\hline
\end{tabular}

Aynı nozul çapı için basınç arttıkça damlacık çapı küçülmüş ve homojenite iyileşmiştir. Şekil 5'e göre işletme basınc1 arttıça damlacık çap1 küçülmüştür. $\mathrm{Bu}$ durum işletme basıncı arttıkça daha iyi bir ilaçlama yapılabileceğini ifade etmektedir. $0.85 \mathrm{~mm}$ çaplı nozul, $70 \mathrm{~cm}$ spreyleme mesafesinde incelendiğinde, en yüksek ve en düşük spreyleme basınçları arasında damlacık çapının \%14.7 azaldığ 1 , homojenitenin ise \%11.7 iyileştiği hesaplanmıştır. Nozul çapının sabit olduğu durum için, 8 bar spreyleme basıncında karakteristik damlacık çapları incelendiğinde, en yüksek ve en düşük spreyleme mesafeleri arasında damlacık çapının \%15.7 azaldığı, homojenitenin ise \%16.8 iyileştiği hesaplanmıştır. $1.50 \mathrm{~mm}$ çaplı nozul, 10 bar spreyleme basıncinda incelendiğinde ise, en yüksek ve en düşük spreyleme mesafeleri arasında damlacık çapının \%28.5 azaldığı, homojenitenin ise \%11.4 iyileştiği hesaplanmıştır.

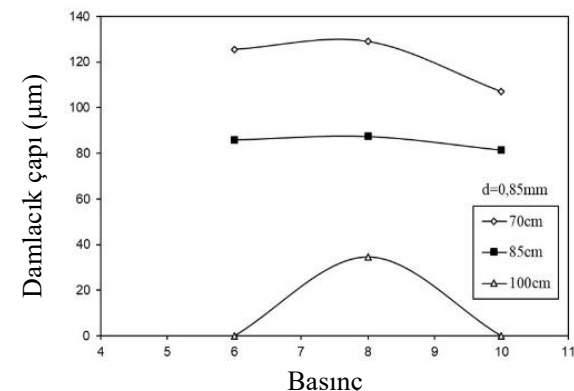

(a)

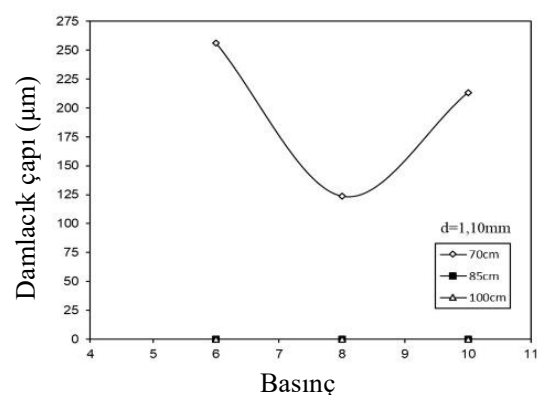

(b)

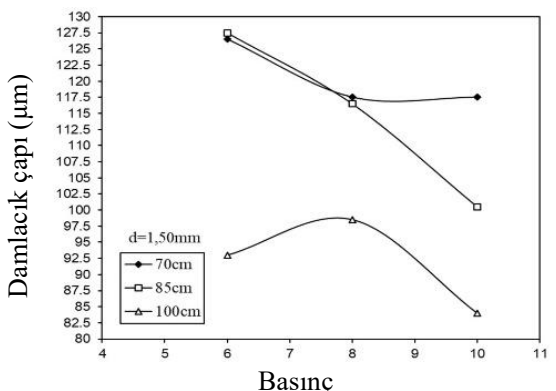

(c)

Şekil 5. Damlacık çapının işletme basıncına göre değişimi. (a) $0.85 \mathrm{~mm}$ orifis çaplı nozul için, (b) $1.10 \mathrm{~mm}$ orifis çaplı nozul için, (c) $1.50 \mathrm{~mm}$ orifis çaplı nozul için

Aynı nozul çapı için aynı spreyleme basıncında, spreyleme mesafesi arttıkça penetrasyon azalmış ve damlacık çapı küçülmüş, bununla birlikte homojenite iyileşmiştir. $1.50 \mathrm{~mm}$ çaplı nozul, 6 bar spreyleme basıncinda incelendiğinde, en yüksek ve en düşük spreyleme mesafeleri arasında damlacık çapının \%28.5 azaldı $\breve{g} 1$, homojenitenin ise \%13.6 iyileştiği görülmektedir (Şekil 6). 


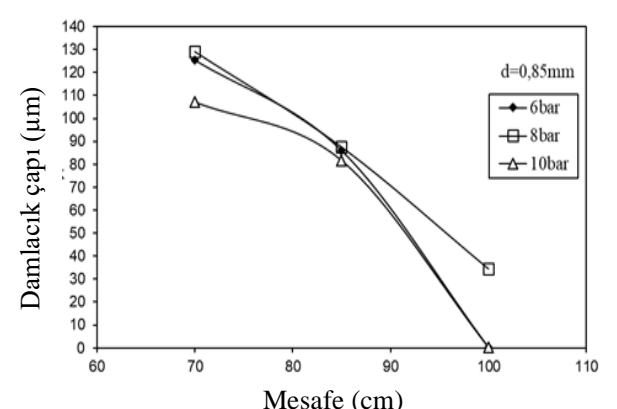

(a)

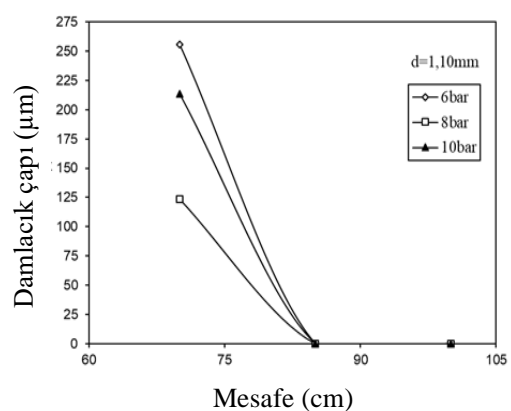

(b)

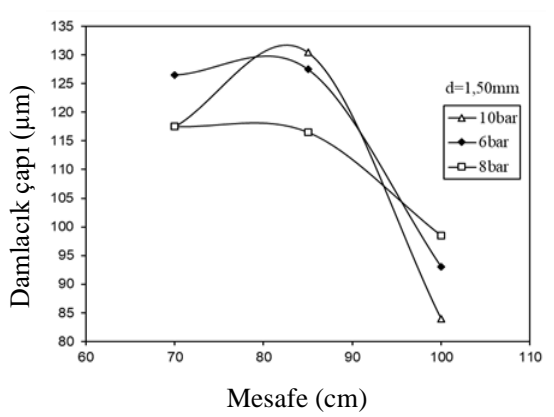

(c)

Şekil 6. Damlacık çapının sprey mesafesine göre değişimi. (a) $0.85 \mathrm{~mm}$ orifis çaplı nozul için, (b) $1.10 \mathrm{~mm}$ orifis çaplı nozul için, (c) $1.50 \mathrm{~mm}$ orifis çaplı nozul için

Aynı spreyleme basıncı ve spreyleme mesafesi için nozul çapları karşılaştırıldığında; orifis çapı arttıkça damlacık çapının arttığı ve homojenite değerinin azaldı ̆̆ 1 gözlemlenmiştir. 10 bar spreyleme basinc1 ve $85 \mathrm{~cm}$ spreyleme mesafesinde en düşük ve en yüksek nozul çapları karşılaştırıldığında; nozul çapı arttıkça damlacık çapının \%60.1 arttığı, homojenitenin ise \%28.4 azaldığg görülmektedir (Şekil 7).

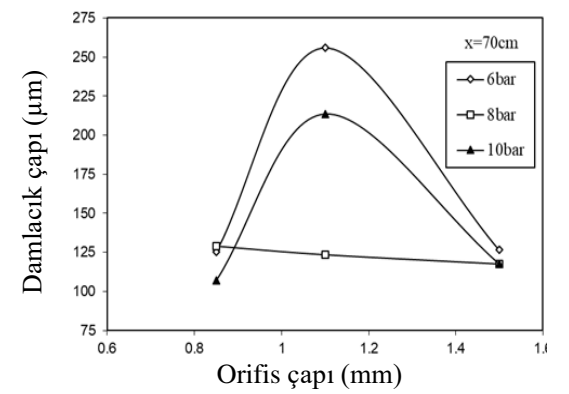

(a)

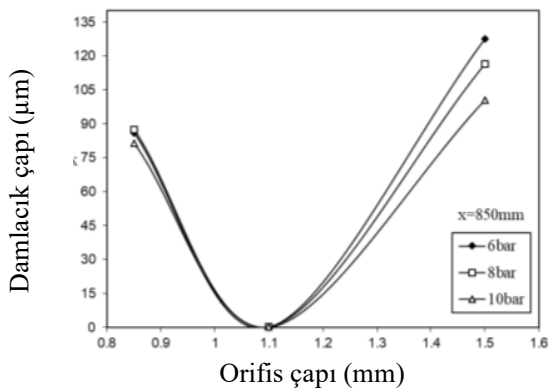

(b)

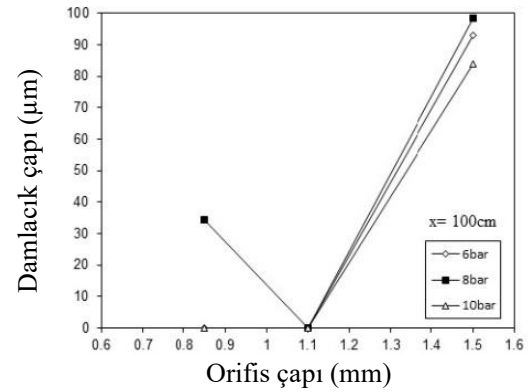

(c)

Şekil 7. Damlacık çapının nozul orifis çapına göre değişimi. (a) $70 \mathrm{~cm}$ mesafe için (b) $85 \mathrm{~cm}$ mesafe için, (c) $100 \mathrm{~cm}$ mesafe için

Farklı nozul çaplarıyla yapılan bu çalışmada en yüksek homojenite $100 \mathrm{~cm}$ spreyleme mesafesinde, 10 bar spreyleme basincinda ve $1.50 \mathrm{~mm}$ çaplı nozulda elde edilmiştir. En düşük homojenite ise $70 \mathrm{~cm}$ spreyleme mesafesinde, 10 bar spreyleme basincinda ve $1.10 \mathrm{~mm}$ çaplı nozulda elde edilmiştir.

\section{Sonuç ve Öneriler}

Atomizasyonda kullanılan nozulların karakteristik damla çapları ile homojenitelerinin aynı spreyleme mesafesinde, çalışma basıncına bağlı olarak değişim gösterdiği görülmektedir. Genel olarak, aynı nozul çap1 ve spreyleme mesafesinde; işletme basıncı artarken karakteristik damla çapları küçülmüş ve homojenlik katsayısı iyileşmiştir. $\mathrm{Bu}$ durum, işletme basıncının artmasıyla daha etkin bir ilaçlama yapılabileceğini ifade etmektedir.

Aynı işletme basıncı ve spreyleme mesafesi için nozul orifis çapları karşılaştırıldığında; orifis çapı arttıkça damlacık çapının arttığı ve homojenlik değerinin azaldığı gözlemlenmiştir. 10 bar basınç ve $85 \mathrm{~cm}$ spreyleme mesafesinde en düşük ve en yüksek orifis çapları karşılaştırıldığında; nozul çapı arttıkça damlacık çapının \%60.1 arttı̆̆1, homojenliğin ise \%28.4 azaldığ hesaplanmıştır. Aynı nozulda basınç arttıkça damlacık çapı küçülmüş ve homojenlik iyileşmiştir.

Sabit işletme basıncında, spreyleme mesafesi arttıkça damlacık çapı küçülmüş ve homojenlik iyileşmiş̧ir. Farklı nozul çaplarında en yüksek homojenlik değeri $100 \mathrm{~cm}$ spreyleme mesafesinde, 10 bar işletme basıncinda ve 1.50 $\mathrm{mm}$ çaplı nozulda elde edilmiştir. En düşük homojenlik ise $70 \mathrm{~cm}$ spreyleme mesafesinde, 10 bar işletme basıncında ve $1.10 \mathrm{~mm}$ orifis çaplı nozulda elde edilmiştir.

Araştırma bulgularına dayalı olarak kesirli faktöriyel tasarımlardan olan Taguchi deney tasarımında optimum noktalar belirlenirken oldukça az sayıdaki deneysel nokta değerleri esas 
alınmaktadır. Özellikle damlacık çapı çalışmalarında bir korelasyona ihtiyaç duyulduğu için kesirli faktöriyel tasarımlarla test elemanlarının davranışlarını tamamen temsil eden bir korelasyon üretmek mümkün değildir. Bunun için istatistiki matematik bilgilerine başvurmak gerekmektedir.

$\mathrm{Bu}$ çalışmada, kesirli faktöriyel tasarımla elde edilen parametrelerin optimum değerlerinin arasında en fazla etkili olanları tam faktöriyel deney tasarım metoduyla incelenmiştir. İlaçlamanın dış etkenlere bağlı (rüzgar hızı, nem, sicaklık, vb.) olmas1 nedeniyle parametre sayıs1 artırilıp optimum şartlar ve parametreler arası etkileşim daha detaylı araştırılabilir. Özellikle akış karakteristiklerini belirlemeye yönelik çalışmalar kompleks çalışmalardır. Bu nedenle bu çalışmada elde edilen damlacık çapı ve homojenlik değerlerinin yanı sıra damla yoğunluğu ve iz maddesinin kullanımıyla maddenin tutunma miktarı hesaplanabilir. $\mathrm{Bu}$ sayede ilaçlama verimliliğiyle ilgili daha detaylı bilgi sahibi olunabilir. Değişik akış simülasyon yöntemleri ve Fluent ve Comsol gibi CFD yazılımları kullanılarak akış olayları sayısal olarak çözülebilir. Ayrıca akış gözlemleme deneyleri yardımıyla; farklı işletme basınçları, spreyleme mesafeleri, sürüklenme miktarları ve debi değerleri vb. etkisinde akım yapısının analiz edilmesi, böylesine dış etkenlere bağlı bir fiziksel olay hakkında bilgi sahibi olmak için oldukça faydalı olacaktır.

\section{References}

Albuz $^{\circledR}$, 2016. Spray Nozzles, Albuz Catalog 2016, http://albuz-spray.com.

Coates, W. ve Palumbo, J., 1997. Deposition, OffTarget Movement, and Efficacy of Capture ${ }^{\mathrm{TM}}$ and Thiodan ${ }^{\mathrm{TM}}$ Applied to Cantaloupes Using Five Sprayers. Applied Engineering in Agriculture, 13(2), 181-188.

Çelen, I.H., Arın, S., Durgut, M.R. ve Okur, E., 2007. Bağlarda Kalıntı ve Damla Dağılımı Üzerinde Pülverizatör İlerleme Hızı Değişiminin Etkisi. Tarımsal Mekanizasyon 24. Ulusal Kongresi, 57 Eylül, Kahramanmaraş, Türkiye, s.407-414.

Çilingir İ. ve Dursun E., 2002. Bitki Koruma Makinaları. Ankara Üniversitesi Ziraat Fakültesi Yayın No:1531, Ders Kitapları Yayın No:484 Ankara, 248s.

Dağ, S.S., Aykaç, V.T., Gündüz, A., Kantarc1, M. ve Şişman, N., 2000. Türkiye'de Tarım İlaçları Endüstrisi ve Geleceği. Kongre 2000 Kitabı,
TMMOB Ziraat Mühendisleri Odası Yayınları, http://www.tmmobzmo.org.tr

FAO, 2017. FAOSTAT, Pesticides Use Online Input Data, http://www.fao.org/faostat/en/\#data

Franz, E., 1993. Spray Coverage Analysis Using a Hand-Held Scanner. Transactions of the ASAE, 36(5), 1271-1278.

Günel, H. ve Öztürk, İ., 2006. Bant İlaçlaması ve Direkt İlaçlama Yapan Üniteler ve Kullanım Alanları. Atatürk Üniversitesi, Ziraat Fakültesi Dergisi, 38(1), 91-95.

Hassen, N.S., Sidik, N.A.C. ve Sheriff, J.M., 2014. Advanced Techniques for Reducing Spray Losses in Agrochemical Application System. Life Science Journal, 11(3), 56-66.

Hipkins, P. ve Grisso, R.B., 2014. Droplet Chart/Selection Guide. Virginia Cooperative Extention, Virginia State University Publication, 442-031.

Hypro $^{\circledR}$, 2018. Hypro Nozzle Catalogue, http://www.hypro-eu.com.

Lechler $^{\circledR}$, 2018. Agricultural Spray Nozzles, 2018 US Catalog, http://www.lechler.de.

Marçal, A.R.S. ve Cunha, M., 2008. Image Processing of Artificial Targets for Automatic Evaluation of Spray Quality. Transactions of the ASABE, 51(3), 811-821.

Matthews, G.A., 2004. How Was The Pesticide. Applied Crop Protection, 23, 651-653.

Nuyttens, D., Baetens, K., De Schampheleire, M. ve Sonck, B. 2007. Effect of Nozzle Type, Size, and Pressure on Spray Droplet Characteristics. Biosystem Engineering, 97(3), 333-345.

Özkan, H.E., Reichard, D.L. ve Ackerman, K.D., 1992. Effect of Orifice Wear on Spray Patterns From Fan Nozzles. Transactions of the ASAE, 35(4), 1091-1097.

Sæbø, O. ve Wighus, R., 2015. Droplet Sizes From Deluge Nozzles. SP Fire Research, SPFR Report A15 107453:1, April 2015, 38 p.

Sanchez-Hermosilla J. ve Medina R., 2004. Adaptive Threshold for Droplet Spot Analysis Using Water-Sensitive Paper. Applied Engineering in Agriculture 20(5), 547-551.

Sayınc1, B., 2016a. The Influence of Strainer Types on the Flow and Droplet Velocity Characteristics of Ceramic Flat -Fan Nozzles. Turkish Journal of Agriculture and Forestry, 40 (1), 25-37.

Sayıncı, B., Demir, B. ve Açık, N., 2019. Pülverizatör Memelerinde Damla Sıklığı ve Pülverizasyon 
Karakteristiklerinin Tahminlenmesi. YYÜ Tarım Bilimleri Dergisi (Yuzuncu Yil University Journal of Agricultural Sciences), 29(3), 458-465.

Sayınc1, B. ve Bastaban, S., 2004. Düşük ve Yüksek Hacim Uygulamalı İlaçlama Aletlerinin Karşılaştırılması: I Tetranychus Urticae Koch [acarina, tetranychidae]'ye Karşı Etkinliklerinin Belirlenmesi. Tarımsal Mekanizasyon 22. Ulusal Kongresi, 8-10 Eylül, Aydin, Türkiye, s.177-184.

Sayınc1, B., Yarpuz-Bozdoğan, N., Yıldız, C. ve Demir, B., 2013. Konik Hüzmeli Memelerde Akıș Katsayısı ve Bazı İșletme Özelliklerinin Belirlenmesi. Tarım Makinaları Bilimleri Dergisi, 9(1), 9-20.

Sidahmed, M.M., Awadalla, H.H. ve Haidar, M.A., 2004. Symmetrical Multi-Foil Shields for Reducing Spray Drift. Biosystems Engineering, 88(3), 305-312.

Srivastava, A.K., Goering, C.E. ve Rohrbach, R.G., 1993. Engineering Principles of Agricultural
Machines. ASAE Textbook Number 6, ISBN 0929355-33-4, $601 \mathrm{p}$.

Sumner, H.R. ve Herzog, G.A., 2000. Assessing the Effectiveness of Air-assisted and Hydraulic Sprayers In Cotton Via Leaf Bioassay. The Journal of Cotton Science, 4, 79-83.

Tanış, M., 2019. Bitkisel İlaçlamada Sprey Karakteristiklerinin Taguchi Yöntemi ile Optimizasyonu. Yüksek Lisans Tezi, Van Yüzüncü Y1l Üniversitesi, Fen Bilimleri Enstitüsü, Van, 36s.

Uremis, I., Bayat, A., Uludag, A., Bozdogan, N., Aksoy, E., Soysal, A. ve Gonen, O., 2004. Studies on Different Herbicide Application Methods in Second Crop Maize Fields. Crop Protection, 23(11), 1137-1144.

Yıldırım, E., 2000. Tarımsal Zararlılarla Mücadele Yöntemleri ve Kullanılan İlaçlar. Atatürk Üniversitesi, Ziraat Fakültesi Yayınları, No: 219, Erzurum, 344 s. 